\title{
The Hybrid Micro-Energy Harvesting, and Energy Saving Using a Newwireless Control Technique for Adjusting Household Cold/Heat in a Smart Room
}

\author{
Bor Jang Tsai* and Cheng Yang Li \\ Department of Mechanical Engineering Chung Hua University, Taiwan \\ (NSC 102-2221-E-216-013) \\ *Corresponding author
}

\begin{abstract}
The laboratory heating thermoelectric generator (TEG) combinesthe phase change material (PCM) via solar panels, to achieve the integration of the electricity generation and adjusting indoor air temperature of buildings,to create "perpetually" powered sensor nodes that enable to harvest ofrequired energy from heat, vibration, thermoelectric, rotating energy, passive flapping foils,piezoelectric and even RF signals and so on. A simulated smart room coupling thethermoelectric and latent heat effects, call thermoelectric generators (TEG) combined with phasechange materials (PCMs)(TEG/PCM), This electricity generation can be used to actuate the fan for adjusting household cool/heat air aswell in a $6.5 \mathrm{~m} \times 4.5 \mathrm{~m} \times 3.2 \mathrm{~m}$ smart building. Comparisons of the power consumptionwith/without installation the TEG/PCM module, and then coupling or without coupling a newwireless "on-off" control technique to sustain a comfortable indoor temperature $22^{\circ} \mathrm{C} \pm 1.5^{\circ} \mathrm{C}$.is the major objective of this study.
\end{abstract}

Keywords-solar panel; thermoelectric generator; phase change materials(PCM)

\section{INTRODUCTION}

This study investigates, experimentally, the use of thermoelectric generators with phase change materials (PCM) to harvest micro-renewable energy [1]. Experimental results in the laboratory and in real loading conditions show that the coupled effects of heat flux (solar radiation), external temperature and convection (wind) significantly influence the micro-energy harvest. Unlike other approaches, the proposed system is able to produce micro-energy by day and by night, thanks to the release of solar heat stored in the PCM during the day. With optimized thermal loading, power generation of 0.8 $\mathrm{mW}$ was achieved by one work unit. The experimental results also show the sensitivity of the proposed work unit to variations in solar radiation and wind, and this indicates that the system (consisting of many work units) would be suitable for use as a sensor and actuator in wireless applications in buildings[2,3]. Semiconductor devices: Polarized solar cells were used to convert photovoltaic-solar energy directly into electrical energy. According to KA. Cook-Chennault, N. Thambi and AM. Sastry [4]. Thermal methods: Thermal energy (temperaturegradient) is converted into electrical energy using, for example, the Seebeck effect [5]; alternatively, time temperature variation is converted through the thermo electric effect. PCM was installed where the sunlight did not irradiate that is the cooling end of TEG [6].At almost the same time,
Tzern T Toh, Paul D Mitcheson, Andrew S Holmes and Eric M Yeatman published "A continuously rotating energy harvester with maximum power point tracking” [7].A micro motor attached to a driver motor was used to provide electrical power to a wireless tachometer used to control the driver motor [8].

\section{PHYSICAL MODEL}

A smart house model (Figure I) is long $6.6 \mathrm{~m}$, width $3 \mathrm{~m}$, high $2.65 \mathrm{~m}$, the main structure of the concrete wall $0.1 \mathrm{~m}$ thick. Sandwich a thick interval $0.05 \mathrm{~m}$ in the floor and ceiling, the upper mezzanine place a long $1.6 \mathrm{~m}$, width $1.9 \mathrm{~m}, 0.04 \mathrm{~m}$ thick of PCM with long $1.8 \mathrm{~m}$, width $2 \mathrm{~m}, 1.4 \mathrm{~m}$ thick thermoelectric generator. And a long $2.1 \mathrm{~m}, 0.07 \mathrm{~m}$, width $2.1 \mathrm{~m}$ thick solar panels [9]. Fig. I gives the introduction of components and equipment of the smart model house. On the right hand side of the building placed a radius $15 \mathrm{~cm}$ duct, duct elbows, long $0.45 \mathrm{~m}$, duct long $1.68 \mathrm{~m}$, placed a fan within a radius of $0.05 \mathrm{~m}$ duct. Disposed within the housing in four different types of micro-energyharvesters, respectively, The electricity generation can be used to actuate the fan for adjusting household cool/heat air as well in a $6.5 \mathrm{mx} 4.5 \mathrm{mx} 3.2 \mathrm{~m}$ smart building to reach and maintain at a comfortable temperature of $24^{\circ} \mathrm{C}$ or so. Therefore, we made use of scaling roughly 1:10 acrylic model (see Figure II) as a simulation of a real house, placed on top of a standard model house for $30 \mathrm{~cm} \times 30 \mathrm{~cm} x 3 \mathrm{~cm}$ of PV solar panels with thermoelectric generator (TEG) and a phase change material (PCM), and installed in the right model house with a diameter of $5 \mathrm{~cm}$ length duct $28 \mathrm{~cm}$ and installed in duct inside diameter of $3 \mathrm{~cm}$ small fan, the other at the top of the acrylic model of a house erected induction halogen as a light source to provide a stable source of solar irradiation in order to simulate a solar panel in day and night time changes in the indoor temperature inside the house. This study with ANSYS/Fluent used numerical approach to simulate this smart house.

\section{SELF-ENERGy Air CONDITIONING DEVICE}

The self-energy home without compressor hot/cold air condition power unit consists of Solar panel/ Thermoelectric generator (TEG)/ Phase change materials (PCM). Receiving energy from sunlight by solar panel to generate electricity, then in addition, as a hot end; heat source of TEG to generate electricity and produce the cooling sink. By using thermoelectric effect, the temperature difference generates electricity. One more technique is using PCM to keep and 
maintenance of cooling temperature effect of PCM as a cooling sink which can increase the thermal efficiency to reach energysaving objective.

\section{A. Solar Panel}

The size of solar panel is $33 \times 33 \times 0.5 \mathrm{~cm}$ (range of electricity generation30x30x5), properties of electricity: Voc: 23V, Vmp: 19V, Isc: $460 \mathrm{~mA}$, Imp:420mA. In this experiment, using a Multi-meter to measure voltage and current every hour, the power generation capacity of this panel is $8 \mathrm{~W}$ (see Figure III).

\section{B. TEG/PCM}

This module of TEG which made up of Bi2Te3 was produced by the ITRI. Its volume is $20 \times 16 \times 2 \mathrm{~cm}$, and consists of 6 units of TEG chips inside the module. On its top installing end cooper tube with water inside as cooling sink, on its bottom side has a heater as heat source. Through the temperature difference, electrons will accumulate on the hot end resulting in different Fermi level, then produce electricity. This experiment used a heater and water to generate temperature difference, then using Multi-meter to measure the voltage and current. In this integration module of TEG/PCM, PCM was embedded in cooling sink of TEG, and maintain a temperature of $-5^{\circ} \mathrm{C}$. Heater will add heat to different pointed temperature.

\section{Solar Panel/TEG/PCM}

The above integration of TEG/PCM which PCM was embedded in the cooling side of TEG and maintain a temperature of $-5^{\circ} \mathrm{C}$. Heater will add heat to different temperatures. In this concept of new design becomes a Solar panel/TEG/PCM module, Solar panel replaced the heater as heat source. Receiving energy from sunlight by solar panel to generate electricity, then in addition, as a hot end; heat source of TEG to generate electricity and produce the cooling sink. Then by using a Multi-meter to measure voltage and current everyhourand using Infrared thermograph measured temperature distribution of each layers of the Solar panel/TEG/PCM module. Fig. IV and Fig. V shown temperature distribution comparisons between each layers, and the highest current of the Solar panel/TEG/PCM module was recorded.

\section{METHODS OF MEASUREMENTS AND ANALYSIS}

Methods of measurements and analysis in this experiment can be divided into 3 portions: Solar panel, TEG/PCM and Solar panel/TEG/PCM. Equipmentsincludes: Multi-meter, illuminator, Infrared thermograph; type of Multi-meter is EXCEL DT-9205, Illuminator is UYIGAO UA1010Band Infrared thermograph is A-J Co. IRC4. These equipments measure voltage, current, power and temperature fields for the above three arrangements individually, in especial, the measurement for Solar panel/TEG/PCM module.

Using Halogen light with illumination 1200 irradiated the Solar panel 10 minutes until the temperature of backside solar panel reach to $50^{\circ} \mathrm{Cunder}$ the indoor temperature $27^{\circ} \mathrm{C}$, then put the hot end of TEG under the backside of solar panel, and PCM installed under the cooling end of TEG, its temperature maintains a temperature of $-5^{\circ} \mathrm{C}$. In final, wait the illumination to 1200 (corresponding to the sunlight illumination under the daytime temperature $32^{\circ} \mathrm{C}$, connect their power generation cathode together and using Multi-meter to measure their voltage and current.

\section{RESUlTS AND DISCUSION}

Experimental results show power measurements of the Solar panel, TEG/PCM and Solar panel/TEG/PCM. Comparisons between them, the highest measurement value of power is voltage $1.5 \mathrm{~V}$ and current $8.1 \mathrm{~A}$. That is to say the highest value of current is the Solar panel/TEG/PCM with 8.1 A. On the contrary, the simple Solar panel generated current 1.79A and TEG/PCM generated current 1.6A. By integrating original Solar panel with thermoelectric effects of TEG and PCM to generate electricity has high power value is clear, then increasing temperature difference will rise the voltage and current, Measurement of power is higher too. In this investigation, the key factor is the keeping and maintenance of cooling temperature effect of PCM as a cooling sink. And from the result reveals PCM receiving heat from the higher temperature ends which are Solar panel and TEG will result in rising temperature, then narrow down temperature difference will lower the power generation capability and affect temperature level of each layers, therefore matching issue of each layers; Solar panel, TEG and PCM need to redesign more seriously.

Figures IV and V indicated the temperature of each layer of the Solar panel/TEG/PCM. To observe how the installing PCM affect unit environmental temperature, an experiment was set by using Halogen light with illumination 1200 irradiated the Solar panel 10 minutes under the indoor temperature $27^{\circ} \mathrm{C}$.

\section{A. Solar Panel}

Figure IV indicated the temperature of Solar panel is $36.8^{\circ} \mathrm{C}$; the average unit environmental temperature is around $29,30^{\circ} \mathrm{C}$ because receiving sunlight energy from the Solar panel rising temperature and causing the temperature of unit environmental temperature increasing too.

\section{B. Solar Panel/TEG/PCM}

Figure $\mathrm{V}$ shown the temperature of Solar panel is $32.7^{\circ} \mathrm{C}$, and the temperature of PCM is $6.2^{\circ} \mathrm{C}$, the average unit environmental temperature is around $26,27^{\circ} \mathrm{C}$, no big difference from indoor temperature. It is not affected by the heat from Solar panel. Main reason is the thermoelectric effects of TEG and PCM, the keeping and maintenance of cooling temperature effect of PCM as a cooling sink heat conduction to all layers including unit environment, TEG and Solar panel, and decrease their temperatures. Resulting in the average unit environmental temperature is around $26,27^{\circ} \mathrm{C}$ lower than that of the simple Solar panel.

\section{Airflow and Thermal Analysis}

The forced convection of the night time. Enviromental conditions: Atmospheric pressure is $1044.8 \mathrm{~Pa}$, the temperature is $20^{\circ}$ Cand wind speed is $6.6 \mathrm{~m} / \mathrm{sec}$. The numerical simulation approach was using when time $\mathrm{t}=1$ minute, 5 minutes, 10 minutes, 20 minutes, 30 minutes and 60 minutes to analyze the change of temperature fields of the simulated smart house respectively.

The temperature fields of the building when $\mathrm{t}=1$ minute in the night time was shown by Figure VI. The driven fan of 
ambient temperature monitoring system has been turn on to blow the cold air through the wind pipe. Temperature of the right hand side of the solar panel begins decreasing. The average temperature is $306.5 \mathrm{~K} \quad\left(33.5^{\circ} \mathrm{C}\right)$. The average temperature on the left hand side of solar panels is $331.2 \mathrm{~K}$ $\left(58.2^{\circ} \mathrm{C}\right)$, the average temperature of surrounding is around $316.8 \mathrm{~K}\left(43.8^{\circ} \mathrm{C}\right)$. The middle of the TEG (thermoelectric generator) temperature is $312.4 \mathrm{~K}\left(29.4^{\circ} \mathrm{C}\right)$. PCM average temperature of $252.8 \mathrm{~K}\left(-20.2^{\circ} \mathrm{C}\right)$, near the PCM, the average temperature is $298.9 \mathrm{~K}\left(25.9^{\circ} \mathrm{C}\right)$. Because of the air flow rate is not too much into the indoor room. There is no significant cooling effect of the indoor temperature is $306.7 \mathrm{~K}\left(33.7^{\circ} \mathrm{C}\right)$. Temperature distribution of case iii was listed in table v. It also shows the using wireless environment temperature monitoring system to drive the fan started to adjust the environment temperature inside the room so that the average temperature dropped $5 \sim 10 \mathrm{~K}$ to reach a comfortable temperature. Temperature vs. time for indoor temperature of the house with natural/forced(fan) convection in day/night time was shown in Figure VII.

\section{Rotation Energy Harvesting Device and Control}

There is a common on-off control method based on room temperature deviations in the air conditioning system (on-off control). In the beginning, deviation around the set point is set in the controller. When the temperature is lower than the "set point - deviation", the fan is closed and the cooling is stopped. When the temperature is higher than the "set point + deviation", the fan is open and the cooling started.

In accordance with the difference between the actual room temperature and the set point, the open ratio of the fan in a single cycle (the fan's open time over the control cycle) can be calculated using the intelligent algorithm, and to control opening and closing the fan in accordance with the open ratio is the last procedure of this intelligent on-off adjustment method. The schematic of the control scheme is shown in Figure VIII.

\section{CONCLUSION}

This investigation proved the unit of Solar panel/TEG/PCM not only generated high power including voltage and current but also can affect unit environmental and indoor temperature of the house. The power can be used to actuate the fan for adjusting household cool/heat air as well in a $6.5 \mathrm{~m} \mathrm{x} 4.5 \mathrm{~m} \mathrm{x}$ $3.2 \mathrm{~m}$ smart building. Comparisons of the power consumption with/without installation the TEG/PCM module, and then coupling or without coupling a new wireless "on-off" control technique to sustain a comfortable indoor temperature $22^{\circ} \mathrm{C} \pm$ $1.5^{\circ} \mathrm{C}$. This unit becomes self-energy home without compressor hot/cold air condition power unit. This study shows that, in a properly designed system, the instant fragmented rotation mechanic energy harvested by the micro motor generates sufficient electrical power to operate the MEMS. This application can reduce the need for batteries and can reduce the waste and pollution generated by producing batteries. The findings are also meaningful for the Taiwan micromechanical industry, which does not currently produce micro motors designed to harvest energy. Hopefully, the combined efforts of universities, the government, and manufactures will establish a new green industry. Four micro-energy harvesters A-D, three self-powered wireless sensor nodes A-C and a fan, and testing a new wireless controltechnique (Wireless “on-off” control technique) for adjusting household cool/heat in a smart building, let its energy savings technology to save around 39\% thermal energy and make the dream of healthy smart, comfortable room come true.

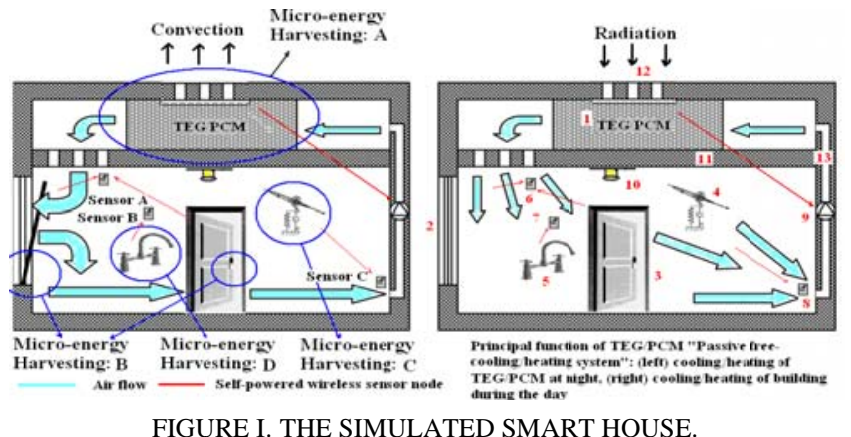

FIGURE I. THE SIMULATED SMART HOUSE.

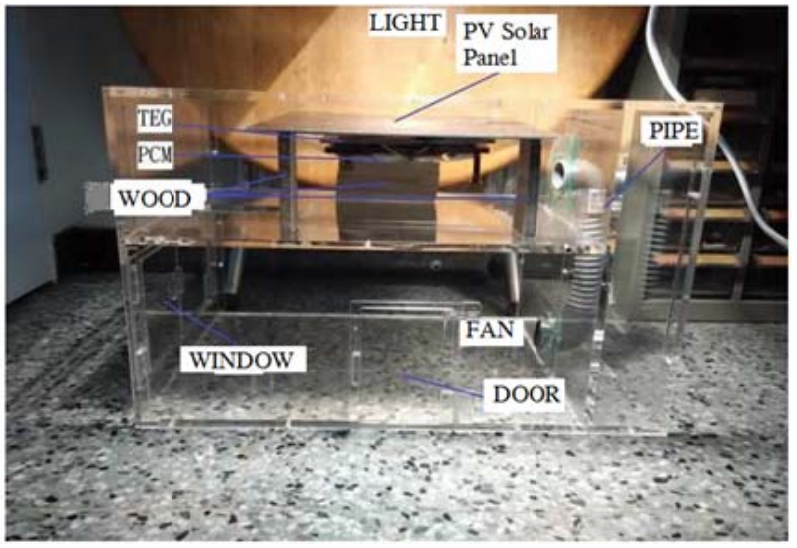

FIGURE II. 1:10 MODEL TEST HOUSE.

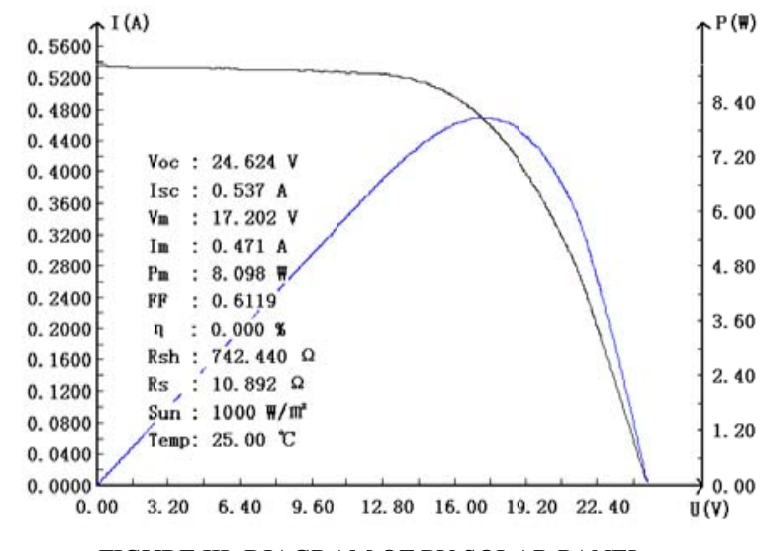

FIGURE III. DIAGRAM OF PV SOLAR PANEL. 


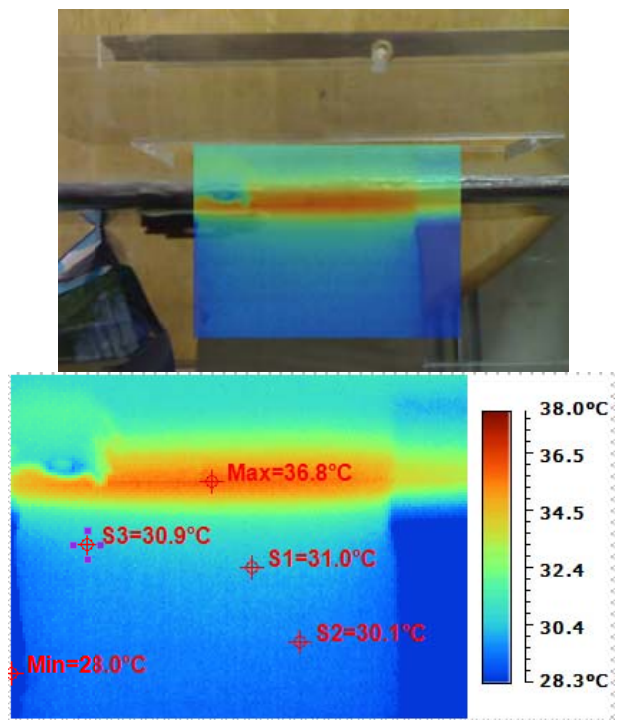

FIGURE IV. TEMPERATURE MEASUREMENT OF TEG/PCM WITH THE HEATER.

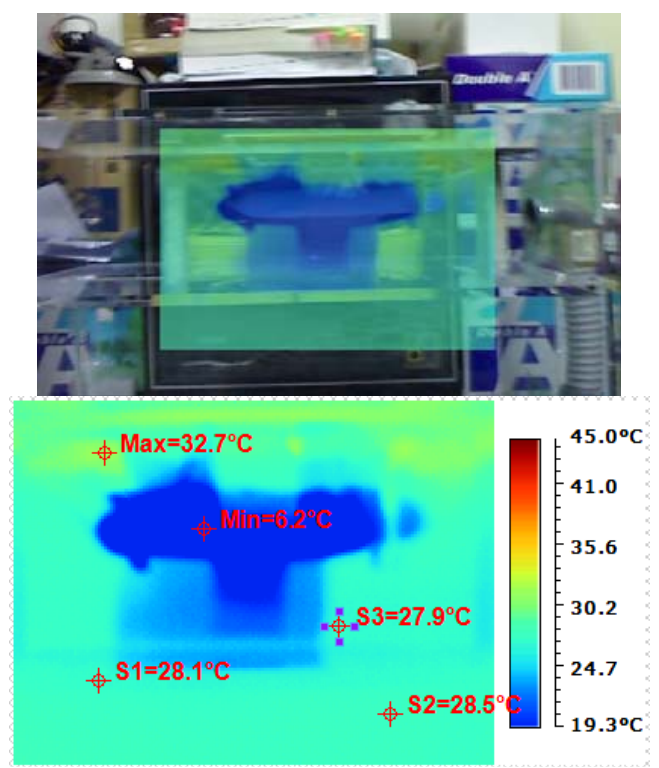

FIGURE V. TEMPERATURE DISTRIBUTION OF THE PV SOLAR PANEL AND MODEL HOUSE (BY INFARED THERMOGRAPH).

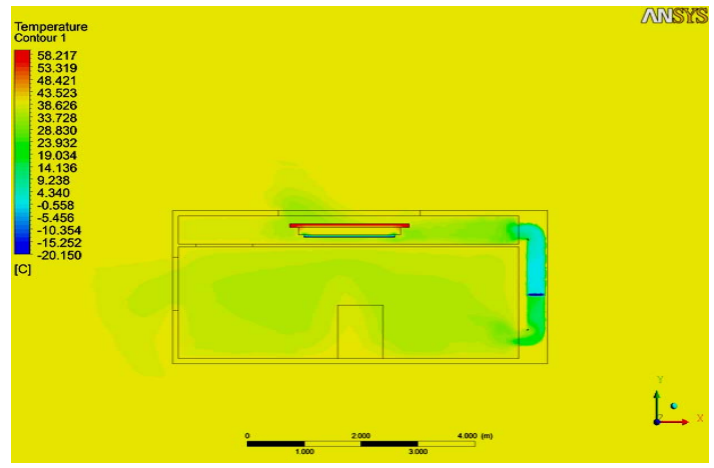

FIGURE VI. TEMPERATURE DISTRIBUTION OF FORCED CONVECTION (DAY) FOR T= 1 MINUTE (WITH FAN).

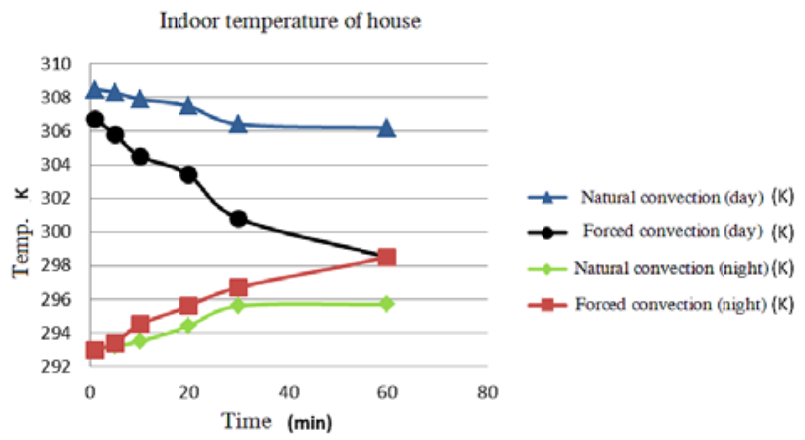

FIGURE VII. COMPARISONS OF T TEMP. CHANGES FOR NATURAL CONVECTION/FORCED CONVECTION AND DAY/NIGHT.

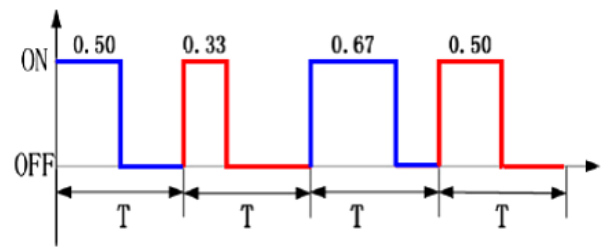

FIGURE VIII. SCHEMATIC DIAGRAM OF TIME ON-OFF REGULATION BASED UPON PREDICTING THE FAN DUTY CYCLE.

\section{ACKNOWLEDGMENT}

The authors acknowledge the support of the Project MOST 102-2221-E-216-013 financially and would like to thank the ITRI for financially/partially supporting this research that this paper can be completed.

\section{REFERENCES}

[1] W. T.Chong, M. S.Naghavi, S.C. Poh, T.M.I. Mahlia, and K. C. Pan, "Techno-economic analysis of a wind-solar hybrid renewable energy system with rainwater collection feature for urban high-rise application," Applied Energy, vol. 88, 2011, pp. 4067-4077.

[2] Amen Agbossou, Q. Zhang, Amen, Gael Sebald and Daniel Guyomar, "Solar micro-energy harvesting based on thermoelectric and latent heat effects.Part I: Theoretical analysis,” Sensors and Actuators A: Physical, vol. 163, 2010, pp. 277-283.

[3] Q. Zhang, Amen Agbossoua, Zhihua Feng and Mathieu Cosnier,"Solar micro-energy harvesting based on thermoelectric and latent heat effects.Part II: Experimental analysis," Sensors and Actuators A: Physical, vol. 163, 2014, pp. 284-290.

[4] KA.Cook-Chennault, N. Thambi and AM. Sastry, "Powering MEMS portable devices - a review of non-regenerative and regenerative power supplysystems withspecial emphasis on piezoelectricenergy harvesting systems,"SmartMaterials and Structures, vol. 17, 2008.

[5] F.D. Rosi,“Thermoelectricity and thermoelectric power generation,”Solid State Electronics, vol. 11, 1968, pp. 833-848.

[6] B. J. Tsai, K. D. Huang and C. H. Lee, "Hybrid structural systems of an active building envelope system(ABE),”Advanced Material Research, vol.168-170, 2010, pp. 2359-2370.

[7] T. T, “A continuously rotating energy harvester with maximum power point tracking, "Journal of Micromechanics and Micro engineering, vol. 18, 2008.

[8] T. T. Toh, P. D. Mitcheson and E. M Yeatman, "Wireless Sensor Node Using a Rotational Energy Harvester with Adaptive Power Conversion, ”PowerMEMS, Washington DC. USA., 2009.

[9] B. J. Tsai, Y.C. Jhang, S. H. Lai“Theoretical performance of integrated photovoltaic /thermal air collector, earth air heat exchanger and greenhouse with a floor of shape-stabilized phase change material: evaluation by energetic analys, ”2010, NSC99-2221-E-216-030. 